\title{
Phase II study of neoadjuvant anthracycline combined with nanoparticle albumin-bound paclitaxel for human epidermal growth factor receptor 2-negative breast cancer
}

\author{
EMI ISHIGAMI, MASAHIRO SAKAKIBARA, JUNTA SAKAKIBARA, TOSHIAKI IWASE, \\ SHOKO HAYAMA, TAKAHITO MASUDA, AYAKO NAKAGAWA, TAKESHI NAGASHIMA, \\ TAKAFUMI SANGAI, HIROSHI FUJIMOTO and MASAYUKI OTSUKA
}

Department of General Surgery, Chiba University Graduate School of Medicine, Chiba, Chiba 260-8670, Japan

Received May 30, 2017; Accepted September 14, 2017

DOI: $10.3892 / \mathrm{mco} .2017 .1464$

\begin{abstract}
Neoadjuvant chemotherapy (NAC) with anthracyclines followed by taxane chemotherapy has become the standard treatment for patients with locally advanced, operable breast cancer. Recently, the efficacy of nanoparticle albumin-bound paclitaxel (nab-PTX) for metastatic breast cancer was reported. However, there are still few studies of a neoadjuvant regimen including nab-PTX. Thus, the present phase II study evaluated the efficacy and safety of 5-fluorouracil, epirubicin and cyclophosphamide (FEC regimen) followed by nab-PTX as neoadjuvant treatment for operable human epidermal growth factor receptor 2 (HER2)-negative breast cancer. Women with operable HER2-negative breast cancer (clinical stage T1a-4N1-3) received 4 cycles of FEC (5-fluorouracil $500 \mathrm{mg} / \mathrm{m}^{2}$, epirubicin $100 \mathrm{mg} / \mathrm{m}^{2}$ and cyclophosphamide $500 \mathrm{mg} / \mathrm{m}^{2}$ every 21 days), followed by 4 cycles of nab-PTX at $260 \mathrm{mg} / \mathrm{m}^{2}$ every 21 days. The patients then underwent mastectomy or breast-conserving surgery (BCS). The primary endpoint was pathological complete response $(\mathrm{pCR})$ rate. The secondary endpoints included clinical response rate, pathological response rate, $\mathrm{BCS}$ rate and safety. A total of 16 patients were evaluated and 3 patients (18\%) achieved pCR (1 patient with estrogen receptor-positive cancer and 2 with estrogen receptor-negative cancer). The pCR rate was 12 and $25 \%$ in patients with estrogen receptor-positive and -negative cancers, respectively. The clinical response rate was $100 \%$ (clinical complete and partial response in 6 and 10 patients, respectively). The BCS rate was $31.25 \%$. Three patients experienced grade 3 neutropenia during FEC therapy, and no grade $3 / 4$ events occurred during nab-PTX
\end{abstract}

Correspondence to: Dr Masahiro Sakakibara, Department of General Surgery, Chiba University Graduate School of Medicine, 1-8-1 Inohana, Chuo-ku, Chiba, Chiba 260-8670, Japan

E-mail: sakaki@faculty.chiba-u.jp

Key words: nanoparticle albumin-bound paclitaxel, neoadjuvant chemotherapy, human epidermal growth factor receptor 2-negative breast cancer, pathological complete response, clinical trial, phase II therapy. Thus, neoadjuvant therapy with FEC followed by nab-PTX for operable HER2-negative breast cancer was found to be a safe and effective option.

\section{Introduction}

Neoadjuvant chemotherapy (NAC) with anthracyclines followed by taxane chemotherapy has been widely recognized as a standard therapy for patients with locally advanced breast cancer. In recent years, this approach has been adopted for the treatment of not only locally advanced, but also resectable breast cancer (1-3). The rate of breast-conserving surgery (BCS) is increased by NAC (4). Regimens including 5-fluorouracil, epirubicin and cyclophosphamide (FEC), epirubicin and cyclophosphamide (EC), or doxorubicin and cyclophosphamide (AC) have been selected as the anthracycline regimens $(2,3,5-7)$, whereas docetaxel or paclitaxel (PTX) have been used as the taxane regimens (8-13). Nanoparticle albumin-bound PTX (nab-PTX) has recently attracted attention as a treatment for advanced metastatic or recurrent breast cancer $(14,15)$.

Nab-PTX is an amorphous protein product made from solvent-free PTX with human albumin. Nab-PTX was developed to decrease toxicity and increase antitumor activity, and it does not require steroid administration to prevent hypersensitivity reactions.

A phase III trial on metastatic breast cancer comparing standard PTX $175 \mathrm{mg} / \mathrm{m}^{2}$ every 3 weeks with nab-PTX $260 \mathrm{mg} / \mathrm{m}^{2}$ every 3 weeks demonstrated significant improvement in the response rate (19 vs. $33 \%$, respectively; $\mathrm{P}=0.001$ ) and in the interval to progression (16.9 vs. 23.0 weeks, respectively) in the nab-PTX arm, with a hazard ratio of $0.75(\mathrm{P}=0.006)(14)$.

Data on neoadjuvant regimens including nab-PTX for HER2-negative breast cancer are limited. To the best of our knowledge, a trial of FEC followed by nab-PTX has not yet been reported. Thus, a phase II trial was undertaken to evaluate the safety and effectiveness of this regimen.

\section{Patients and methods}

Patients. This was a single-center, prospective, single-arm, phase II trial. Patients with histologically confirmed invasive 
breast cancer by core biopsy with lymph node-positive, HER2-negative, operable invasive breast cancer (clinical stage T1-4N1-3) were considered eligible. All the tumors were evaluated locally for expression of estrogen receptor (ER), progesterone receptor (PgR) and HER2. ER and PgR were defined as positive with positive staining of $>1 \%$. HER2 was defined as positive with either positivity on immunohistochemistry of $3+$, or demonstration of amplification on fluorescence in situ hybridization of $>2$. Other eligibility criteria included Eastern Cooperative Oncology group (EGOG) performance status $\leq 1$; age $\geq 20$ years; hemoglobin level $\geq 8.0 \mathrm{~g} / \mathrm{dl}$; white blood cell count $3,000-12,000 / \mathrm{mm}^{3}$; platelet count $\geq 10 \times 10^{4} / \mathrm{mm}^{3}$; creatinine level $\leq 1.5 \mathrm{mg} / \mathrm{d}$; normal total liver function, with bilirubin $\leq 1.5 \mathrm{mg} / \mathrm{dl}$, aspartate aminotransferase $<100 \mathrm{IU} / 1$ and alanine aminotransferase $<100 \mathrm{IU} / \mathrm{l}$; and normal cardiac function.

Patients who had received any previous treatment were excluded. Other exclusion criteria included severe heart disease, diarrhea, ileus, intestinal paralysis, poorly controlled diabetes, poorly controlled angina, myocardial infarction, heart failure within 6 months, interstitial lung fibrosis, cerebrovascular disorder, symptomatic brain metastases, gastrointestinal bleeding requiring blood transfusion, severe bone marrow suppression, severe renal disorder, severe liver disorder, severe pleural effusion, severe ascites, previous hypersensitivity to nab-PTX or albumin, pentostatin treatment, other active cancers, any infectious disease, pregnancy or lactation, mental disease, or steroid therapy.

This trial was approved by the Ethics Committee of the Chiba University Graduate School of Medicine and all the patients provided written informed consent prior to inclusion (registered at UMIN000007724).

Therapy. The patients received 4 cycles of FEC (5-fluorouracil $500 \mathrm{mg} / \mathrm{m}^{2}$, epirubicin $100 \mathrm{mg} / \mathrm{m}^{2}$ and cyclophosphamide $500 \mathrm{mg} / \mathrm{m}^{2}$ every 21 days) followed by 4 cycles of nab-PTX at $260 \mathrm{mg} / \mathrm{m}^{2}$ every 21 days. Adverse events were graded according to the National Cancer Institute Common Terminology Criteria for Adverse Events, version 4.0 (https://evs.nci.nih. gov/ftp1/CTCAE/CTCAE_4.03_2010-06-14_QuickReference_5x7. pdf). Preventive granulocyte colony-stimulating factor was not administered. The patients underwent surgery 4-6 weeks after the chemotherapy.

Endpoint. The primary endpoint was pathological complete response (pCR) rate, defined as no histological residual invasive tumor cells in the breast and axillary lymph nodes (ypT0/Tis and ypN0). There was no case of ypT0/Tis and ypN $\mathrm{pN}^{+}$.

The secondary endpoints were clinical response rate, pathological response rate, BCS rate and safety. Clinical response rates were evaluated by ultrasonography, computed tomography and magnetic resonance imaging according to the Response Evaluation Criteria in Solid Tumors guidelines, version 1.1 (https://ctep.cancer.gov/protocoldevelopment/docs/recist_guideline.pdf).

Statistical analysis. Robidoux et al reported that the phase II trial National Surgical Adjuvant Breast and Bowel Project (NSABP) FB-AX-003 of neoadjuvant weekly nab-PTX followed by FEC for locally advanced breast cancer demon- strated a pCR rate of $17 \%$ in the HER2-negative subset (16). In another previous study, NSABP B-27 of AC followed by docetaxel demonstrated a pCR rate of $26 \%$ (3). For the present study, a threshold pCR rate of $10 \%$, an expected pCR rate of $25 \%$, an $\alpha$ error of $5 \%$, and a power of $80 \%$ were set based on these previous studies. Consequently, an accrual of 36 patients was planned to produce a minimum of 33 evaluable patients.

\section{Results}

Patient population. Between November 2011 and October 2013, 19 patients were enrolled; 3 patients were excluded due to withdrawal of consent prior to treatment initiation and 16 patients were finally considered evaluable for efficacy and safety of this study treatment.

The patients' characteristics are summarized in Table I. The median age was 54 years, 3 patients had stage II breast cancer, and 13 patients had stage III breast cancer. Of the 16 patients, $8(50 \%)$ had luminal type B breast cancer, and $8(50 \%)$ had triple-negative breast cancer.

Treatment administration and study completion. A total of $10(62 \%)$ patients received all 8 planned cycles without delays or missed doses; 3 (18\%) patients missed doses and/or required delays during FEC therapy due to adverse events; 4 patients missed doses $\left(185-220 \mathrm{mg} / \mathrm{m}^{2}\right)$ during the first administration of nab-PTX.

Clinical and pathological assessments. The pCR rate was $18.75 \%$ (3/16 patients); $12.5 \%$ (1/8 patients) had luminal type $B$ and $25 \%$ (2/8 patients) had triple-negative breast cancer. The clinical response rate was $100 \%$ (clinical complete and partial response in 6 and 10 patients, respectively) (Table II). The pathological treatment effect was as follows: Grade 1a, $n=8$; grade $1 b, n=3$; grade $2 a, n=1$; grade $2 b, n=1$; and grade $3, n=3$ (Table III). The BCS rate was $31.25 \%$.

Safety profile. The adverse events are listed in Table IV. A total of 3 patients developed grade 3 neutropenia. Grade 3 adverse events occurred during FEC therapy, but were not observed during nab-PTX therapy. Nausea and vomiting occurred more frequently during FEC.

All the patients experienced grade $1 / 2$ muscle pain and peripheral neuropathy during nab-PTX treatment. Grade 3/4 non-hematological toxicity did not occur with either regimen. No unexpected severe adverse events occurred.

\section{Discussion}

To the best of our knowledge, this is the first report of a phase II study of neoadjuvant nab-PTX with the FEC regimen for HER2-negative breast cancer.

High pCR rates with neoadjuvant regimens have been reported for HER2-positive breast cancer (17), but not for HER2-negative breast cancer. In the NSABP FB-AX-003 phase II trial, the pCR rate for HER2-positive cancer with a 24-week regimen of weekly nab-PTX plus trastuzumab, followed by FEC and trastuzumab, was 58\%, whereas the pCR rate of the regimen without trastuzumab for HER2-negative cancer was $17 \%$ (16). Nab-PTX has been shown to be effective in 
Table I. Patient characteristics $(n=16)$.

\begin{tabular}{|c|c|}
\hline Characteristics & $\mathrm{n}(\%)$ \\
\hline \multicolumn{2}{|l|}{ Age, years } \\
\hline Median & 54 \\
\hline Range & $31-73$ \\
\hline \multicolumn{2}{|c|}{ Menopausal status, n (\%) } \\
\hline Premenopausal & $7(43.75)$ \\
\hline Post-menopausal & $9(56.25)$ \\
\hline \multicolumn{2}{|c|}{ ECOG performance status } \\
\hline 0 & $16(100.00)$ \\
\hline 1 & $0(0.00)$ \\
\hline \multicolumn{2}{|c|}{ Clinical tumor stage, n (\%) } \\
\hline $\mathrm{T} 1$ & $1(6.25)$ \\
\hline $\mathrm{T} 2$ & $7(43.75)$ \\
\hline $\mathrm{T} 3$ & $3(18.75)$ \\
\hline $\mathrm{T} 4$ & $5(31.25)$ \\
\hline \multicolumn{2}{|c|}{ Clinical nodal stage, n (\%) } \\
\hline No & $0(0.00)$ \\
\hline N1 & $8(50.00)$ \\
\hline $\mathrm{N} 2$ & $4(25.00)$ \\
\hline \multicolumn{2}{|l|}{ N3 } \\
\hline \multicolumn{2}{|l|}{ Clinical stage, n (\%) } \\
\hline T1N3 & $1(6.25)$ \\
\hline $\mathrm{T} 2 \mathrm{~N} 1$ & $3(18.75)$ \\
\hline $\mathrm{T} 2 \mathrm{~N} 2$ & $2(12.50)$ \\
\hline $\mathrm{T} 2 \mathrm{~N} 3$ & $2(12.50)$ \\
\hline $\mathrm{T} 3 \mathrm{~N} 1$ & $3(18.75)$ \\
\hline T4N1 & $2(12.50)$ \\
\hline T4N2 & $2(12.50)$ \\
\hline T4N3 & $1(6.25)$ \\
\hline \multicolumn{2}{|c|}{ Receptor status (all HER2/neu-negative) } \\
\hline Triple-negative & $8(50.00)$ \\
\hline ER- and PgR-positive & \\
\hline
\end{tabular}

ECOG, Eastern Cooperative Oncology Group; ER, estrogen receptor; $\mathrm{PgR}$, progesterone receptor; HER2, human epidermal growth factor receptor 2 .

Table II. Summary of efficacy outcomes $(n=16)$.

\begin{tabular}{lc}
\hline Endpoint & $\mathrm{n}(\%)$ \\
\hline Histological response & \\
pCR in the breast and axilla & $3(18.75)$ \\
pCR in the breast & $0(0.00)$ \\
Clinical response rate prior to surgery & \\
CR & $6(37.50)$ \\
PR & $10(62.50)$ \\
SD & $0(0.00)$ \\
PD & $0(0.00)$ \\
\hline
\end{tabular}

pCR, pathological complete response; PR, partial response; SD, stable disease; $\mathrm{PD}$, progressive disease.
Table III. Histological response.

\begin{tabular}{lcc}
\hline & \multicolumn{2}{c}{ Type of cancer } \\
\cline { 2 - 3 } $\begin{array}{l}\text { Histological } \\
\text { response }\end{array}$ & $\begin{array}{c}\text { Triple-negative }(\mathrm{n}=8) \\
\mathrm{n}(\%)\end{array}$ & $\begin{array}{c}\text { Luminal }(\mathrm{n}=8) \\
\mathrm{n}(\%)\end{array}$ \\
\hline 0 & 0 & $0(0.0)$ \\
$1 \mathrm{a}$ & $4(50.0)$ & $4(50.0)$ \\
$1 \mathrm{~b}$ & $2(25.0)$ & $1(12.5)$ \\
$2 \mathrm{a}$ & 0 & $1(12.5)$ \\
$2 \mathrm{~b}$ & 0 & $1(12.5)$ \\
3 & $2(25.0)$ & $1(12.5)$ \\
\hline
\end{tabular}

Table IV. Safety profile.

\begin{tabular}{lcc}
\hline & \multicolumn{2}{c}{ Grade, $\mathrm{n}(\%)$} \\
\cline { 2 - 3 } Adverse events & All grades & Grade 3/4 \\
\hline Anemia & $14(87.50)$ & $0(0.00)$ \\
Leukopenia & $6(37.50)$ & $3(18.75)$ \\
Neutropenia & $5(31.25)$ & $3(18.75)$ \\
Hepatic dysfunction & $11(68.75)$ & $0(0.00)$ \\
Mouth ulcer & $7(43.75)$ & $0(0.00)$ \\
Nausea & $16(100.00)$ & $0(0.00)$ \\
Diarrhea & $1(6.25)$ & $0(0.00)$ \\
Dysgeusia & $13(81.25)$ & $0(0.00)$ \\
Hair loss & $16(100.00)$ & $0(0.00)$ \\
Muscle pain & $16(100.00)$ & $0(0.00)$ \\
Peripheral neuropathy & $16(100.00)$ & $0(0.00)$ \\
\hline
\end{tabular}

patients with HER2-negative metastatic breast cancer $(14,15)$. Neoadjuvant FEC followed by nab-PTX has not yet been reported. Thus, the safety and effectiveness of this regimen as neoadjuvant chemotherapy for operable HER2-negative breast cancer needed to be assessed. Thus, a single-center, phase II study was performed to evaluate the safety and pCR of this regimen. In our hospital, the $\mathrm{pCR}$ rate for $\mathrm{AC}$ followed by tri-weekly PTX was $5.9 \%$, for FEC followed by tri-weekly PTX it was $13.2 \%$, and for FEC followed by nab-PTX it was $18.75 \%$. Shimada et al reported that the pCR rate for nab-PTX followed by EC was $5.7 \%$ (18). Two explanations were considered as plausible for the low pCR rate in that study: First, FEC therapy may be more effective compared with EC therapy. Second, $64 \%$ of patients in that study had ER-positive breast cancer, which may have included some patients with luminal type A breast cancer. In the present study, $50 \%$ of the patients had ER-positive breast cancer.

Of note, in the present study, the clinical response rate was $100 \%$. Shimada et al reported that nab-PTX followed by EC achieved a clinical response rate of $75.5 \%$ (18). We considered that the reason for the lower clinical response rate in that study was also the difference between FEC and EC therapy. Second, that study included several patients with ER-positive 
breast cancer. The efficacy of FEC followed by nab-PTX as neoadjuvant chemotherapy for patients with HER2-negative operable cancer may be higher compared with that of methods used to date when the pCR rate is evaluated.

Three patients (18.75\%) had grade 3-4 AEs, and all patients had grade 1-2 AEs. During nab-PTX treatment, no patient had grade 3-4 AEs. Thus, FEC did not appear to adversely affect nab-PTX therapy. A previous trial of AC followed by PTX reported that grade 3-4 AEs during PTX included neurosensory toxicity in $15 \%$, neuromotor toxicity in $7 \%$, neurosensory or neuromotor toxicity in $18 \%$, arthralgia and/or myalgia in $12 \%$, day 1 granulocytopenia in $3 \%$, and febrile neutropenia in $3 \%$ of the patients (12). Another previous trial of AC followed by PTX reported grade 4 neutropenia in $16 \%$ during PTX therapy, and 3\% patients required hospitalization due to AEs during PTX therapy (11). They reported that a severe hypersensitivity reaction occurred in $1 \%$ of patients during PTX administration (11). However, there were no grade $\geq 3$ AEs during nab-PTX in the present trial. All the patients had grade 1-2 AEs, but the FEC regimen followed by nab-PTX appeared to have good tolerability. The present study was prematurely terminated due to its poor accrual rate. The time to enroll patients was not extended, as we had started another neoadjuvant trial including nab-PTX for patients with HER2-negative cancer.

In conclusion, FEC followed by nab-PTX as neoadjuvant treatment for HER2-negative operable breast cancer appeared to be effective and well-tolerated. This regimen exhibited better efficacy compared with the standard anthracycline followed by taxane chemotherapy regimens, whereas, in terms of side effects, this combination may be among the safest.

\section{Acknowledgements}

The authors would like to thank the patients, nurses and physicians at Chiba University Hospital.

\section{References}

1. Wolmark N, Wang J, Mamounas E, Bryant J and Fisher B Preoperative chemotherapy in patients with operable breast cancer: Nine-year results from national surgical adjuvant breast and bowel project B-18. J Natl Cancer Inst Monogr 30: 96-102, 2001.

2. Bear HD, Anderson S, Brown A, Smith R, Mamounas EP, Fisher B, Margolese R, Theoret H, Soran A, Wickerham DL, et al: The effect on tumor response of adding sequential preoperative docetaxel to preoperative doxorubicin and cyclophosphamide: Preliminary results from National Surgical Adjuvant Breast and Bowel Project Protocol B-27. J Clin Oncol 21: 4165-4174, 2003.

3. Rastogi P, Anderson SJ, Bear HD, Geyer CE, Kahlenberg MS, Robidoux A, Margolese RG, Hoehn JL, Vogel VG, Dakhil SR, et al: Preoperative chemotherapy: Updates of national surgical adjuvant breast and bowel project protocols B-18 and B-27. J Clin Oncol 26: 778-785, 2008.

4. Gralow JR, Burstein HJ, Wood W, Hortobagyi GN, Gianni L von Minckwitz G, Buzdar AU, Smith IE, Symmans WF, Singh B and Winer EP: Preoperative therapy in invasive breast cancer: Pathologic assessment and systemic therapy issues in operable disease. J Clin Oncol 26: 814-819, 2008.
5. Early Breast Cancer Trialists' Collaborative Group (EBCTCG), Peto R, Davies C, Godwin J, Gray R, Pan HC, Clarke M, Cutter D, Darby S, McGale P, et al: Comparisons between different polychemotherapy regimens for early breast cancer: meta-analyses of long-term outcome among 100,000 women in 123 randomised trials. Lancet 379: 432-444, 2012.

6. FrenchAdjuvantStudy Group: Benefit of a high-dose epirubicin regimen in adjuvant chemotherapy for node-positive breast cancer patients with poor prognostic factors: 5-year follow-up results of French Adjuvant Study Group 05 randomized trial. J Clin Oncol 19: 602-611, 2001.

7. Bonneterre J, Roché H, Kerbrat P, Brémond A, Fumoleau P, Namer M, Goudier MJ, Schraub S, Fargeot $P$ and Chapelle-Marcillac I: Epirubicin increases long-term survival in adjuvant chemotherapy of patients with poor-prognosis, node-positive, early breast cancer: 10-year follow-up results of the french adjuvant study group 05 randomized trial. J Clin Oncol 23: 2686-2693, 2005

8. De Laurentiis M, Cancello G, D'Agostino D, Giuliano M, Giordano A, Montagna E, Lauria R, Forestieri V, Esposito A, Esposito A, et al: Taxane-based combinations as adjuvant chemotherapy of early breast cancer: A meta-analysis of randomized trials. J Clin Oncol 26: 44-53, 2008.

9. Martin M, Pienkowski T, Mackey J, Pawlicki M, Guastalla JP, Weaver C, Tomiak E, Al-Tweigeri T, Chap L, Juhos E, et al: Adjuvant docetaxel for node-positive breast cancer. N Engl J Med 352: 2302-2313, 2005.

10. Roché H, Fumoleau P, Spielmann M, Canon JL, Delozier T, Serin D, Symann M, Kerbrat P, Soulié P, Eichler F, et al: Sequential adjuvant epirubicin-based and docetaxel chemotherapy for node-positive breast cancer patients: The FNCLCC PACS 01 trial. J Clin Oncol 24: 5664-5671, 2006.

11. Henderson IC, Berry DA, Demetri GD, Cirrincione CT, Goldstein LJ, Martino S, Ingle JN, Cooper MR, Hayes DF, Tkaczuk KH, et al: Improved outcomes from adding sequential paclitaxel but not from escalating doxorubicin dose in an adjuvant chemotherapy regimen for patients with node-positive primary breast cancer. J Clin Oncol 21: 976-983, 2003.

12. Mamounas EP, Bryant J, Lembersky B, Fehrenbacher L, Sedlacek SM, Fisher B, Wickerham DL, Yothers G, Soran A and Wolmark N: Paclitaxel after doxorubicin plus cyclophosphamide as adjuvant chemotherapy for node-positive breast cancer: Results from NSABP B-28. J Clin Oncol 23: 3686-3696, 2005.

13. Buzdar AU, Singletary SE, Valero V, Booser DJ, Ibrahim NK, Rahman Z, Theriault RL, Walters R, Rivera E, Smith TL, et al: Evaluation of paclitaxel in adjuvant chemotherapy for patients with operable breast cancer: Preliminary data of a prospective randomized trial. Clin Cancer Res 8: 1073-1079, 2002.

14. Gradishar WJ, Tjulandin S, Davidson N, Shaw H, Desai N, Bhar P, Hawkins M and O'Shaughnessy J: Phase III trial of nanoparticle albumin-bound paclitaxel compared with polyethylated castor oil-based paclitaxel in women with breast cancer. J Clin Oncol 23: 7794-7803, 2005.

15. Blum JL, Savin MA, Edelman G, Pippen JE, Robert NJ, Geister BV, Kirby RL, Clawson A and O'Shaughnessy JA: Phase II study of weekly albumin-bound paclitaxel for patients with metastatic breast cancer heavily pretreated with taxanes. Clin Breast Cancer 7: 850-856, 2007.

16. Robidoux A, Buzdar AU, Quinaux E, Jacobs S, Rastogi P, Fourchotte V, Younan RJ, Pajon ER, Shalaby IA, Desai AM, et al: A phase II neoadjuvant trial of sequential nanoparticle albumin-bound paclitaxel followed by 5 -fluorouracil/ epirubicin/cyclophosphamide in locally advanced breast cancer. Clin Breast Cancer 10: 81-86, 2010.

17. Valachis A, Mauri D, Polyzos NP, Chlouverakis G, Mavroudis D and Georgoulias V: Trastuzumab combined to neoadjuvant chemotherapy in patients with HER2-positive breast cancer: A systematic review and meta-analysis. Breast 20: 485-490, 2011.

18. ShimadaH,UedaS,SaekiT,Shigekawa T,TakeuchiH,HirokawaE, Sugitani I, Sugiyama M, Takahashi T, Matsuura K, et al: Neoadjuvant triweekly nanoparticle albumin-bound paclitaxel followed by epirubicin and cyclophosphamide for Stage II/III HER2-negative breast cancer: Evaluation of efficacy and safety. Jpn J Clin Oncol 45: 642-649, 2015. 